\title{
Treatment of mental slowness: How to evaluate treatment effects. A systematic review of outcome measures
}

Citation for published version (APA):

Winkens, I., van Heugten, C. M., Fasotti, L., \& Wade, D. T. (2011). Treatment of mental slowness: How to evaluate treatment effects. A systematic review of outcome measures. Neuropsychological Rehabilitation, 21(6), 860-883. https://doi.org/10.1080/09602011.2011.627267

Document status and date:

Published: 01/01/2011

DOI:

10.1080/09602011.2011.627267

Document Version:

Publisher's PDF, also known as Version of record

Document license:

Taverne

Please check the document version of this publication:

- A submitted manuscript is the version of the article upon submission and before peer-review. There can be important differences between the submitted version and the official published version of record.

People interested in the research are advised to contact the author for the final version of the publication, or visit the DOI to the publisher's website.

- The final author version and the galley proof are versions of the publication after peer review.

- The final published version features the final layout of the paper including the volume, issue and page numbers.

Link to publication

\footnotetext{
General rights rights.

- You may freely distribute the URL identifying the publication in the public portal. please follow below link for the End User Agreement:

www.umlib.nl/taverne-license

Take down policy

If you believe that this document breaches copyright please contact us at:

repository@maastrichtuniversity.nl

providing details and we will investigate your claim.
}

Copyright and moral rights for the publications made accessible in the public portal are retained by the authors and/or other copyright owners and it is a condition of accessing publications that users recognise and abide by the legal requirements associated with these

- Users may download and print one copy of any publication from the public portal for the purpose of private study or research.

- You may not further distribute the material or use it for any profit-making activity or commercial gain

If the publication is distributed under the terms of Article 25fa of the Dutch Copyright Act, indicated by the "Taverne" license above, 


\section{Neuropsychological Rehabilitation}

\section{Treatment of mental slowness: How to evaluate treatment effects. A systematic review of outcome measures}

leke Winkens , Caroline M. Van Heugten , Luciano Fasotti \& Derick T. Wade

To cite this article: leke Winkens, Caroline M. Van Heugten, Luciano Fasotti \& Derick T. Wade (2011) Treatment of mental slowness: How to evaluate treatment effects. A systematic review of outcome measures, Neuropsychological Rehabilitation, 21:6, 860-883, DOI: $10.1080 / 09602011.2011 .627267$

To link to this article: https://doi.org/10.1080/09602011.2011.627267

曲 Published online: 13 Dec 2011.

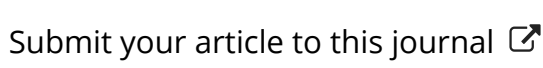

山 Article views: 814

Q View related articles ¿

Citing articles: 1 View citing articles 줄 


\title{
Treatment of mental slowness: How to evaluate treatment effects. A systematic review of outcome measures
}

\author{
Ieke Winkens ${ }^{1}$, Caroline M. Van Heugten ${ }^{1,2}$, \\ Luciano Fasotti ${ }^{3,4}$, and Derick T. Wade ${ }^{5,6}$ \\ ${ }^{1}$ School for Mental Health and Neurosciences, Maastricht University, \\ The Netherlands \\ ${ }^{2}$ Department of Neuropsychology and Psychopharmacology, Maastricht \\ University, The Netherlands \\ ${ }^{3}$ Sint Maartenskliniek Research, Development \& Education, Nijmegen, \\ The Netherlands \\ ${ }^{4}$ NICI, Nijmegen Institute for Cognition and Information, Nijmegen, \\ The Netherlands \\ ${ }^{5}$ Oxford Centre for Enablement, Oxford, UK \\ ${ }^{6}$ Adelante, Hoensbroek, The Netherlands
}

Brain-damaged patients with slow mental processes may be taught compensatory strategies that might enable them to minimise disabilities and participation problems in daily life. The effects of the application of compensatory strategies should be measured in these domains of functioning. We systematically reviewed existing outcome measures used to evaluate the consequences of mental slowness. We classified measures into four categories: (1) standardised neuropsychological tests; (2) tests or questionnaires measuring general cognitive impairment; (3) measures of general everyday functioning; and (4) measures of everyday consequences of mental slowness. The majority of measures for mental slowness focus on performance in specific cognitive tasks. We found seven studies that used nine measures which focused on task-related or perceived limitations in everyday functioning. We discuss a

Correspondence should be addressed to Ieke Winkens, Department of Psychiatry and Neuropsychology, School for Mental Health and Neuroscience, Faculty of Health, Medicine and Life Sciences, Maastricht University. P.O. Box 616, 6200 MD Maastricht, The Netherlands. E-mail: i.winkens@maastrichtuniversity.nl

(C) 2011 Psychology Press, an imprint of the Taylor \& Francis Group, an Informa business http://www.psypress.com/neurorehab http://dx.doi.org/10.1080/09602011.2011.627267 
series of reasons why measures of the perception of slowness (including the perceived consequences of slowness) and the performance in everyday activities should be used. Such measures may be more likely to detect change or differences in performance and are certainly more relevant to patients.

Keywords: Mental slowness; Outcome measures.

\section{INTRODUCTION}

In modern society it has become important to think and to react quickly. We drive our cars through heavy traffic, we attend hectic meetings at work in which we need to make important decisions within minutes, we are expected to make quick decisions by shop assistants, and we watch action movies starring many characters acting in complex plots.

For patients with acquired brain damage, fast information processing is often difficult or even impossible. After stroke, for example, $50 \%$ to $70 \%$ of patients complain about "mental slowness" (Hochstenbach, Mulder, Van Limbeek, Donders, \& Schoonderwaldt, 1998; Rasquin et al., 2004). Patients experiencing mental slowness may present with a range of problems and complaints. There may be an externally observed slowness, with patients showing slowed performance on neuropsychological tasks. Or patients may have problems in everyday situations with events proceeding at a rate they cannot control, such as conversations, driving a vehicle or watching television. And there may be a feeling within the person that things happen too quickly: one can no longer mentally keep up with cognitive demands being made by external events. This in turn may lead to fatigue, altered mood and irritability (Winkens, Van Heugten, Fasotti, Duits, \& Wade, 2006; Winkens, Van Heugten, Fasotti, \& Wade, 2009).

Research into the management and rehabilitation of "mental slowness" requires both an understanding of the nature of slow information processing and its neural mechanisms and an understanding of the functional consequences of any slowness. The selection of appropriate rehabilitation methods and appropriate outcome measures to evaluate the effects of these methods should be based on a sound theory. Several theories explaining the mechanisms of information processing and problems arising with timely information processing have been developed, and these theories may help to understand the occurrence of slowness after acquired brain injury, and how effective treatments might be designed.

In connectionist models, information or knowledge is represented by an associative network consisting of a large set of interconnected nodes (Anderson, 1993). Each node has a certain threshold activation level and 
when the level of this particular node is exceeded, that node (and its associated information or process) is available for use. The nodes are related to each other by links. The retrieval speed of information or knowledge is strongly determined by the degree of modal activation and the strength of the links between the nodes: retrieval of information is fastest and most accurate when the nodes are highly activated and the links between the nodes are strong. The activation of nodes and the strength of the links get higher each time they are used, but both decay over time if not used. This would imply that in novel situations (driving a car for the first time), the links between nodes are still weak and activation of the node is still low. In well-practised situations (being an experienced driver), the links between the nodes are strong, and activation of the node is high. Processing of novel information thus will require more effort and more time (Timmerman \& Brouwer, 1999).

Salthouse (1996) explains the occurrence of problems by means of the Processing-Speed Theory. The fundamental assumption in this theory is that speed of processing is a relatively general process limiting performance in many cognitive tasks. Two distinct mechanisms are postulated to be responsible for the relation between speed and cognition. The first mechanism is the so-called "limited time mechanism". The basis for this mechanism is simply that the time to perform higher-order cognitive processes is greatly restricted when a large proportion of the available time is occupied by the execution of earlier processes. This mechanism is primarily relevant when there are external time limits: relevant operations are executed too slowly to be successfully completed within the available time (for example, hitting the brakes of the car to prevent a collision). In simple tasks, speed of performance is likely to be the primary determinant of individual differences in performance. In more complicated tasks it is likely that the quality or accuracy of performance is affected by the number of operations that can be carried out in the available time. If complex operations are dependent on the products of simpler operations, and fewer of these products are available because of a slower execution speed, problems can be expected to occur.

Salthouse suggested a second mechanism, the "simultaneity mechanism". The key assumption is that information decreases in availability over time as a function of decay or displacement (i.e., the products of early processing may be lost or may have become inaccurate before later processing is ready to use it). Processing deficits could emerge because of discrepancies between the time course of loss of information and the speed with which critical operations, such as elaboration, rehearsal or abstraction, can be executed. To the extent that this is the case, relevant information may no longer be available at the time it is needed. Moreover, under rapidly changing conditions, the information may no longer be accurate by the time it becomes available (for example, in fast conversations with several people). In both cases, when the rate of executing operations is slow, information provided is less likely to be 
useful. This will occur regardless of the amount of time allowed for processing because the critical limitations are based on internal dynamics.

Another interesting idea was developed by Posner and Snyder (1975). These authors distinguish two qualitatively different processes: controlled processing and automatic processing. This idea was further elaborated by Shiffrin and Schneider (1977). Controlled processes are slow (they take more time), are effortful (they require attention), are generally serial (they occur sequentially), and are limited by the capacity of short-term memory. They are used when dealing with novel situations (e.g., driving a car for the first time). Factors that reduce information processing capacity (such as fatigue or motivation) affect these controlled processes adversely, and may lead to slower or less accurate output.

Automatic processes on the other hand do not require attention; they occur in parallel, are fast, are fairly effortless and are of effectively unlimited capacity. They underlie the performance of well-developed, skilled behaviours and require considerable training to develop (e.g., becoming an experienced driver). Shiffrin and Schneider suggest that a "divided attention deficit" occurs when too much task-relevant information requiring conscious processing is offered in a short amount of time. When having a conversation during driving, for example, the limited capacity of the system for controlled processing may be exceeded. Relevant signals may be missed, and required responses may not be given (in the worst case scenario leading to a traffic accident).

Van Zomeren and Spikman (2003) have interpreted empirical data from patients with traumatic brain injury within this theory. Patients may, for example, complain that they have difficulty listening to a teacher while at the same time making notes. In such tasks, information processing capacity has to be divided over several different subtasks: listening to the teacher, reading what is written on the blackboard, and making notes. After acquired brain injury, subtasks that used to be automatic have to be processed in a more controlled way and hence require more time and effort. The automatic aspect is lost or at least reduced. Brain-damaged patients may have fewer attentional resources to be divided over the subtasks at hand. Consequently, the limited capacity of the slow, serial, controlled processing is likely to be exceeded. In this case the patients may experience time pressure and will complain that they can no longer perform two tasks at the same time.

In order to teach brain-damaged patients to compensate for their reduced information processing capacity and speed in time pressure tasks and to prevent or to manage time pressure in their daily lives, Fasotti et al. developed Time Pressure Management training (Fasotti, Kovacs, Eling, \& Brouwer, 2000). Time Pressure Management is a compensatory strategy training based on the idea of controlled versus automated processing that focuses on improving performance in everyday situations. Hence, effects of Time Pressure Management should in fact be measured in terms of observation 
of the restructured activity and in terms of general questionnaires about perceived consequences.

For a randomised controlled study of Time Pressure Management techniques (now completed, see Winkens, Van Heugten, Wade, Habets, \& Fasotti, 2009), we wished to identify measures that would be (1) relevant to people who had slowed or limited cognitive processing speed secondary to brain damage, and (2) focused on performance of activities so that the effects of compensatory strategies could be detected. We started with a systematic search for outcome measures used to study "mental slowness", eventually selecting those that satisfied our two criteria given above. We restricted our search to stroke and traumatic brain injury because (1) they were the conditions most likely to have been studied and (2) it limited the number of papers identified at the initial stage to a manageable number.

\section{METHOD}

A literature search was conducted in four electronic databases: PubMed, PsycINFO, Embase and CINAHL (1982 to February 2010). The following inclusion criteria were applied: (1) participants were clinically diagnosed as patients with traumatic brain injury (TBI) or stroke; and (2) papers included outcome measures used to study mental slowness or speed of information processing. Exclusion criteria were: (1) non-English language papers; (2) theoretical or review papers; (3) animal studies; and (4) studies involving children (i.e., aged below 19 years).

Combinations of the following keywords were used: type of cognitive disorder or function (mental slowness, speed of information processing) and type of brain injury (stroke or TBI). Both controlled vocabulary words (MESH terms, Thesaurus terms) and free text words were combined in our searches. Details of the search are shown in the Appendix. In addition, reference lists from identified articles were hand searched to complete the initial list of references.

The search, which included papers indexed up to February 2010, identified 1556 published papers. All papers were independently reviewed on title and abstract by two people (IW, $\mathrm{CvH}$ ). Initially there was disagreement over 146 out of 1556 papers. However, this high rate appeared to be due to indistinct criteria: there was uncertainty whether or not to exclude case studies, and papers about patient groups with silent cerebral infarcts, cerebral white matter lesions, or vascular dementia, as well as papers about motor slowness or general IQ tests in which processing speed was one of several processes measured. After discussion it was decided to exclude these papers resulting in disagreement over only 11 papers $(<1 \%)$.

The revised inclusion criteria were: (1) participants were clinically diagnosed as patients with traumatic brain injury (TBI) or stroke; (2) papers 
included outcome measures used to study mental slowness or speed of information processing. The revised exclusion criteria were: (1) non-English language papers; (2) theoretical or review papers; (3) participants were clinically diagnosed as patients with silent cerebral infarcts, cerebral white matter lesions, or vascular dementia; (4) papers about motor slowness or general IQ tests in which processing speed was one of several processes measured; (5) animal studies; and (6) studies involving children (i.e., aged below 19 years).

For the 11 papers and for 17 other papers that could not be rejected or included just by reading the abstract, full texts were obtained and a decision was made after reading the full text. Data from the full texts of the selected papers were then extracted for analysis. After removing 384 duplicates, another 851 papers were excluded according to the exclusion criteria described in the method section. Figure 1 summarises the search results.

Eventually, 321 papers were eligible for inclusion. A variety of outcome measures for assessing mental slowness were used. Some studies focused on slowness in particular; others focused on themes such as depression, or vocational outcome after rehabilitation and studied mental slowness as a covariate or predictor. Still other studies focused on cognitive functioning in general, using general questionnaires or measures. Slowness was then just one of many items studied.

One person (IW) classified the measurement instruments into four categories. In cases of doubt, a second person $(\mathrm{CvH})$ was asked to give her opinion:

- Standardised neuropsychological tests.

- Tests or questionnaires measuring general cognitive impairments.

- Measures of general everyday functioning: Assessments that were not specifically designed to measure consequences of mental slowness, but that were used to measure performance of activities or perceived functioning in areas likely to be affected by mental slowness.

- Measures of everyday consequences of mental slowness: Assessments that by design measured the everyday consequences of mental slowness (either in performance of activities, or in the secondary consequences of performing the activities).

\section{RESULTS}

Several studies used measures of two or more different categories. Of the 321 studies, 274 used standardised neuropsychological tests of cognitive processing speed. Twenty-three studies used tests or questionnaires measuring general cognitive impairments. Forty-one studies used general measures of everyday functioning. Only seven studies used specific measures of the everyday consequences of mental slowness. 


1556 abstracts
retrieved by the
original search

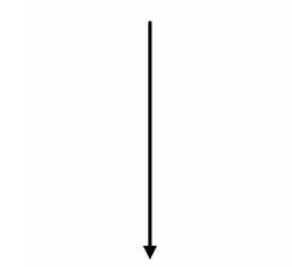

324 full text articles retrieved for review
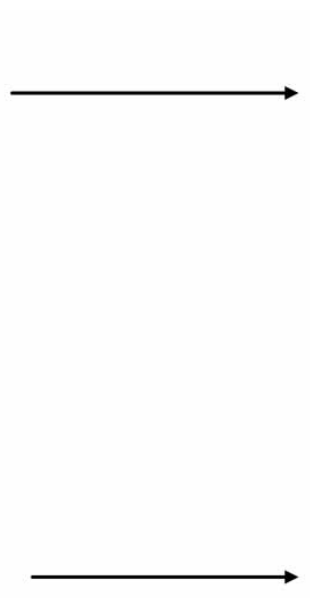

1232 excluded:

- theoretical or review papers: 65

- studies not using outcome measures for mental slowness or speed of information processing: 168

- studies involving children: 100

- animal studies: 18

- subjects not diagnosed with stroke or TBI: 497

- duplicates: 384

3 excluded:

- Theoretical or review papers: 2

- Subjects not diagnosed with stroke or TBI: 1

321 papers included in the analysis*:

- 274 studies used standardised neuropsychological tests

- 23 studies used tests or questionnaires measuring general cognitive impairments

- 41 studies used measures designed to detect general everyday functioning

- 7 studies used measures designed to detect everyday consequences of mental slowness

* Some studies used more than one type of instrument

Figure 1. Search results.

\section{Standardised neuropsychological tests}

The tests used most often were simple and choice reaction time tasks, but also common were tests traditionally developed for evaluating the presence of deficits in attention, such as coding tasks (e.g., the Symbol Digit Modalities Test and the Symbol Digit Substitution Test); serial addition tasks (e.g., the Paced Auditory Serial Addition Test); and the Stroop Color Word Task and Trail Making Test (see, for example, Felmingham, Baguley, \& Green, 2004; Geurts, Knoop, \& Van Limbeek, 1999; O'Jile et al., 2006; Timmerman \& Brouwer, 1999). For these tests the variable of interest is the time needed to perform the task, or the number of correct answers given within a 
certain time limit. It is difficult to describe exactly how often a particular test was used. Sometimes it was only mentioned that neuropsychological tests for speed were part of a cognitive screening battery. More often, tests were not mentioned by name in the abstract.

\section{Tests or questionnaires measuring general cognitive impairments}

Examples of such instruments are ImPACT computerised test battery, the Rivermead Post-Concussion Symptoms Questionnaire, and the Neurobehavioral Rating Scale (e.g., Fazio, Lovell, Pardini, \& Collins, 2007; Heitger et al., 2006; Lippert-Gruner, Kuchta, Hellmich, \& Klug, 2006).

\section{Measures of general everyday functioning}

Examples of these measures are the Community Integration Questionnaire, driving tasks and the Fatigue Severity Scale (e.g., Brouwer, Withaar, Tant, \& Van Zomeren, 2002; Millis, Rosenthal, \& Lourie, 1994; Ponsford \& Ziino, 2003).

\section{Measures of everyday consequences of mental slowness}

Table 1 lists all instruments that were found.

We were primarily interested in measures used to detect and/or measure the everyday consequences of mental slowness, assessing limitations in daily activities as well as the patient's experience of slowness. Further details are given here on the seven studies that included measures from category four.

Ponsford and Kinsella (1988) used a rating scale completed by the patient's occupational therapist, the Rating Scale of Attentional Behaviours, to evaluate the effects of a computer-mediated programme for the remediation of deficits in speed of information processing. The rating scale contained items reflecting a broad range of observable clinical behaviours, linked conceptually with aspects of attention such as slowness, distractibility, and attention to detail. Each item was scored from 0 to 4 reflecting the frequency with which it was apparent $(0=$ not at all; $4=$ always $)$.

Additionally, a 30-minute video of the patient performing a clerical task in the occupational therapy department was used as a measure of the effects of training on overt attentional behaviours such as distractibility and ability to sustain attention to a task in a situation that was more closely related to functional activities. We did not find any data on how the video was scored. The scale developed is valid as a measure of attentional behaviour. It is quick and simple to administer. It shows modest, but statistically significant correlations with neuropsychological measures of attention and a high level of internal consistency. Test-retest reliability is strong $(r=.93)$ but the correlations between scores made by different raters (speech therapists versus 
TABLE 1

Instruments used for assessing mental slowness

\begin{tabular}{|c|c|c|}
\hline Category & Instruments & References \\
\hline \multicolumn{3}{|c|}{$\begin{array}{l}\text { Standardised } \\
\quad \text { neuropsychological tests }\end{array}$} \\
\hline & $\begin{array}{l}\text { Simple and choice reaction time } \\
\text { tasks }\end{array}$ & $\begin{array}{l}\text { See, for example, Ballard et al. } \\
\text { (2003); Felmingham et al. } \\
\text { (2004); Gerritsen et al. } \\
\text { (2003); Korda \& Douglas } \\
\text { (1997); Ponsford \& Kinsella } \\
\text { (1992); Pouthas \& Perbal } \\
\text { (2004); Stuss et al. (1989); } \\
\text { Timmerman \& Brouwer } \\
\text { (1999) }\end{array}$ \\
\hline & RT-distraction task & Spikman et al. (1999) \\
\hline & Cued response time tasks & $\begin{array}{l}\text { See, for example, Sosnoff et al. } \\
\text { (2007) }\end{array}$ \\
\hline & Visual recognition tasks & $\begin{array}{l}\text { See, for example, Sosnoff et al. } \\
\text { (2007) }\end{array}$ \\
\hline & Symbol scanning tasks & $\begin{array}{l}\text { See, for example, Sosnoff et al. } \\
\text { (2007) }\end{array}$ \\
\hline & Symbol Digit Substitution Test & $\begin{array}{l}\text { See, for example, Geurts et al. } \\
\text { (1999); Hinton-Bayre et al. } \\
\text { (1997) }\end{array}$ \\
\hline & Symbol Digit Modalities Test & $\begin{array}{l}\text { See, for example, Felmingham } \\
\text { et al. (2004); Hinton-Bayre } \\
\text { et al. (1997); Ponsford \& } \\
\text { Kinsella (1992) }\end{array}$ \\
\hline & Coding Task & Dik et al. (2000) \\
\hline & $\begin{array}{l}\text { Paced Auditory Serial Addition } \\
\text { Test }\end{array}$ & $\begin{array}{l}\text { See, for example, Laidlaw } \\
\text { (1993); O'Jile et al. (2006); } \\
\text { Ponsford \& Kinsella (1992) }\end{array}$ \\
\hline & $\begin{array}{l}\text { Paced Visual Serial Addition } \\
\text { Test }\end{array}$ & Fos et al. (2000) \\
\hline & Stroop Color Word Test & $\begin{array}{l}\text { See, for example, Felmingham } \\
\text { et al. (2004); Leskela et al., } \\
\text { (1999); Ponsford \& Kinsella } \\
\text { (1992) }\end{array}$ \\
\hline & $\begin{array}{l}\text { Posner's Covert Orienting of } \\
\text { Attention Task }\end{array}$ & Bate et al. (2001) \\
\hline & $\begin{array}{l}\text { Covert Orientation of Visual } \\
\text { Attention Task }\end{array}$ & $\begin{array}{l}\text { See, for example, Petry et al. } \\
\text { (1994) }\end{array}$ \\
\hline & Trail Making Test & $\begin{array}{l}\text { See, for example, Felmingham } \\
\quad \text { et al. (2004); Johnstone et al. } \\
\quad \text { (1999); Leskela et al. (1999) }\end{array}$ \\
\hline & $\begin{array}{l}\text { Sequential Number Connection } \\
\text { Test }\end{array}$ & Ebner et al. (1986) \\
\hline
\end{tabular}


TABLE 1

Continued

\begin{tabular}{|c|c|c|}
\hline Category & Instruments & References \\
\hline & Tapping tasks & Pouthas \& Perbal (2004) \\
\hline & Useful Field of View Test & $\begin{array}{l}\text { See, for example, Fisk \& } \\
\text { Mennemeier (2006); Mazer } \\
\text { et al. (2001) }\end{array}$ \\
\hline & Concussion Resolution Index & Erlanger et al. (2003) \\
\hline & Cognitive Performance Test & Loranger et al. (2000) \\
\hline & Sternberg Memory Task & Gron (1996) \\
\hline & Semantic categorisation task & Gerritsen et al. (2003) \\
\hline & $\begin{array}{l}\text { Controlled Oral Word } \\
\text { Association Test }\end{array}$ & Carlson (1996) \\
\hline & Word fluency tasks & $\begin{array}{l}\text { See for example Crawford et al. } \\
\text { (2007); Leskela et al. (1999) }\end{array}$ \\
\hline & Naming tasks & Barrow (2001) \\
\hline & Speed of Comprehension Test & $\begin{array}{l}\text { See for example, Hinton-Bayre } \\
\text { et al. (1997); Ponsford et al. } \\
\text { (2000) }\end{array}$ \\
\hline & $\begin{array}{l}\text { Ruff } 2 \& 7 \text { Selective Attention } \\
\text { Test }\end{array}$ & Ruff et al. (1992) \\
\hline & $\begin{array}{l}\text { Computerised Test of } \\
\text { Information Processing }\end{array}$ & Tombaugh et al. (2007) \\
\hline & $\begin{array}{l}\text { Orientation Log and Cognitive } \\
\text { Log }\end{array}$ & Lee et al. (2004) \\
\hline \multicolumn{3}{|c|}{$\begin{array}{l}\text { Test or questionnaires } \\
\quad \text { measuring general } \\
\text { cognitive impairments }\end{array}$} \\
\hline & $\begin{array}{l}\text { ImPACT computerised test } \\
\text { battery }\end{array}$ & $\begin{array}{l}\text { See, for example, Fazio et al. } \\
\text { (2007); Iverson et al. (2006) }\end{array}$ \\
\hline & Cognitive Stability Index & Erlanger et al. (2002) \\
\hline & $\begin{array}{l}\text { Automated Neuropsychological } \\
\text { Assessment Metrics }\end{array}$ & Bleiberg et al. (2000) \\
\hline & $\begin{array}{l}\text { Dean-Woodcock } \\
\text { Neuropsychological } \\
\text { Assessment System }\end{array}$ & Lang (2000) \\
\hline & $\begin{array}{l}\text { Halstead-Reitan } \\
\text { Neuropsychological Test } \\
\text { Battery }\end{array}$ & Collins \& Long (1996) \\
\hline & $\begin{array}{l}\text { Human Performance } \\
\text { Measurement System - Basic } \\
\text { Elements Performance }\end{array}$ & Grigsby et al. (1995) \\
\hline & $\begin{array}{l}\text { Rivermead Post-Concussion } \\
\text { Symptoms Questionnaire }\end{array}$ & Heitger et al. (2006) \\
\hline & Neurobehavioral Rating Scale & $\begin{array}{l}\text { See, for example, De Guise et al. } \\
\text { (2005); Lippert-Gruner et al. } \\
\text { (2006) }\end{array}$ \\
\hline
\end{tabular}


TABLE 1

Continued

\begin{tabular}{|c|c|c|}
\hline Category & Instruments & References \\
\hline & $\begin{array}{r}\text { Checklist for Cognitive and } \\
\text { Emotional Consequences }\end{array}$ & Duits et al. (2008) \\
\hline \multicolumn{3}{|c|}{$\begin{array}{l}\text { Measures of general } \\
\text { everyday functioning }\end{array}$} \\
\hline & $\begin{array}{l}\text { Community Integration } \\
\text { Questionnaire }\end{array}$ & Millis et al. (1994) \\
\hline & $\begin{array}{l}\text { Neurobehavioural Functioning } \\
\text { Inventory }\end{array}$ & Bay \& Donders (2008) \\
\hline & $\begin{array}{l}\text { Extended Glasgow Outcome } \\
\text { Scale }\end{array}$ & Ponsford et al. (2008) \\
\hline & Psychosocial Disability Scale & Tate \& Broe (1999) \\
\hline & $\begin{array}{l}\text { Return to work or school } \\
\text { (retrieved from patients' } \\
\text { rehabilitation programme } \\
\text { charts) }\end{array}$ & $\begin{array}{l}\text { Klonoff et al. (2007); Watt \& } \\
\text { Penn (2000) }\end{array}$ \\
\hline & $\begin{array}{l}\text { MacAuley Outcome Scale } \\
\text { (productivity outcome) }\end{array}$ & Brown et al. (1996) \\
\hline & Driving skill & $\begin{array}{l}\text { Brouwer et al. (2002); } \\
\text { Formisano et al. (2001); } \\
\text { Korteling (1990) }\end{array}$ \\
\hline & Driving simulator & Galski et al. (1997) \\
\hline & Fatigue Severity Scale & Ponsford \& Ziino (2003) \\
\hline & Apathy Evaluation Scale & Brodaty et al. (2005) \\
\hline \multicolumn{3}{|c|}{$\begin{array}{l}\text { Measures of everyday } \\
\text { consequences of mental } \\
\text { slowness }\end{array}$} \\
\hline & $\begin{array}{l}\text { Video observation of functional } \\
\text { task performance }\end{array}$ & Ponsford \& Kinsella (1988) \\
\hline & $\begin{array}{l}\text { Rating Scale of Attentional } \\
\text { Behaviours }\end{array}$ & $\begin{array}{l}\text { Ponsford and Kinsella (1988); } \\
\text { Whyte et al. (2004) }\end{array}$ \\
\hline & $\begin{array}{l}\text { Observation of functional task } \\
\text { performance }\end{array}$ & $\begin{array}{l}\text { Fasotti et al. (2000); Winkens, } \\
\text { Van Heugten, Wade, Habets, } \\
\text { \& Fasotti (2009) }\end{array}$ \\
\hline & $\begin{array}{l}\text { Computer-simulated virtual } \\
\text { reality task }\end{array}$ & Zhang et al. (2001) \\
\hline & $\begin{array}{l}\text { Attention Rating and Monitoring } \\
\text { Scale }\end{array}$ & Cicerone (2002) \\
\hline & Inattentive Behaviour Task & Whyte et al. (2004) \\
\hline & $\begin{array}{l}\text { Real-time observational scoring } \\
\text { of attentiveness }\end{array}$ & Whyte et al. (2004) \\
\hline & Test of Everyday Attention & Whyte et al. (2004) \\
\hline & Mental Slowness Questionnaire & $\begin{array}{c}\text { Winkens, Van Heugten, Wade, } \\
\text { Habets, \& Fasotti (2009) }\end{array}$ \\
\hline & $\begin{array}{l}\text { Mental Slowness Observation } \\
\text { Test }\end{array}$ & $\begin{array}{c}\text { Winkens, Van Heugten, Wade, } \\
\text { Habets, \& Fasotti (2009) }\end{array}$ \\
\hline
\end{tabular}


occupational therapists) are much lower ( $r=.5$ to .6) (Ponsford \& Kinsella, 1991).

Fasotti et al. (2000) used two video tasks to evaluate the effects of Time Pressure Management. In both tasks patients watched a video. In one task, patients were told they were about to buy a waterbed. The video showed a shop assistant giving them more information about this item. The instructions emphasised that the patients should remember as much information as possible and they were allowed to do anything to make this easier, except for writing down the information. In the other task, a set of instructions was given to the patient on how to use part of a software package. In this task the purpose was to remember as much as possible in order to perform an assignment later. At the end the patient was asked to execute the task. For both tasks, the strategies the patient used to deal with standardised disturbances, such as a simultaneous radio broadcast and a telephone call, were recorded on a behaviour observation list (for example, asking if the radio could be turned off, interrupting the video, reiterating the information, etc.). For the waterbed task, the patient's reproduction score was calculated by dividing the reproduced items by the total number of information units presented in the task. For the software task, the reproduction score was based on the number of steps reached in the execution. We did not find data on clinical utility, reliability or validity of these tasks.

Zhang et al. (2001) used a computer-simulated virtual reality environment to assess the ability of patients to process and sequence information involved in basic activities of daily living. This environment simulated a typical kitchen with standard objects and appliances. Subjects navigated through the environment by using a computer cursor or touch screen. The simulated task involved preparing a bowl of soup. This task was divided into 30 steps, categorised as follows: information processing, problem solving, logical sequencing, and speed of responding. The overall assessment score was based on the number of correct responses and the time needed to complete daily living tasks representing the speed of processing information and finishing tasks.

The virtual reality system shows adequate reliability and construct validity as a method of assessment in persons with brain damage. The stability of performance using the simulated virtual environment was estimated with intraclass correlation coefficients (ICCs). The ICC value for total performance, based on all steps involved in the meal preparation task, was .76 $(p<.01)$. The construct validity of the simulated environment was examined by correlating performance in the virtual environment with that in an actual kitchen $(r=.63, p<.01)$, an evaluation by an occupational therapist $(r=.30$, $p=.05$ for meal preparation; $r=.40, p=.01$ for cognitive subskills), and neuropsychological tests $(r=.56, p<.01$ for the full-scale IQ; $r=.40$, $p<.01$ for the verbal IQ; $\mathrm{r}=.56, p<.01$ for the performance IQ). 
Finally, a multiple regression analysis revealed that the virtual reality environment test was a predictor for the actual kitchen assessment (beta $=$ $.35, p=.01$ ) (Zhang et al., 2003).

Cicerone (2002) used a self-report measure, the Attention Rating and Monitoring Scale, to evaluate the effectiveness of an intervention for processing speed and working memory efficiency. The intervention emphasised the conscious and deliberate use of strategies to allocate attentional resources effectively and to manage the rate of rapidly presented information during task performance. The Attention Rating and Monitoring Scale attempts to foster the application of strategies outside of the immediate treatment situation. The scale consists of 15 items relating to problems with concentration, mental effort, and cognitive symptoms associated with attention difficulties. Participants rated how often they had experienced each difficulty in their day-to-day functioning over the past two weeks. Although the formal psychometric properties of this scale have not been examined, it has been shown to discriminate between a group of patients diagnosed with mild traumatic brain injury and a group of non-injured controls.

Whyte et al. (2004) used a wide range of attentional measures to evaluate the effects of methylphenidate on a variety of aspects of attention, including mental processing speed, ranging from impairments to activity levels. The measures included computerised and paper-and-pencil tests of attention, but also videotaped records of individuals working in a distracting environment (Inattentive Behaviour Task; Whyte et al., 2004), real-time observational scoring of attentiveness in a classroom environment (Whyte et al., 2004), and the Ponsford and Kinsella (1991) Rating Scale of Attentional Behaviours. The effect of mental processing speed on actual activities was measured by means of two subtests of the Test of Everyday Attention: locating items on a map, and looking for phone numbers in a directory; the number of targets circled and time per target are recorded (Robertson, Ward, Ridgeway, \& Nimmo-Smith, 1996). The videotaped records of the Inattentive Behaviour Task showed excellent inter-rater reliability with Cohen's Kappa scores ranging from 0.82 to 1.0 (Whyte et al., 2004). Observational scoring of classroom attentiveness showed average inter-rater agreement of $99 \%$ and Cohen's Kappa scores ranged from 0.65 to 1.0 (Whyte et al., 2004). The subtests of the Test of Everyday Attention have been shown to have high test-retest reliability and to correlate significantly with existing measures of attention (Robertson et al., 1996).

Winkens, Van Heugten, Wade, Habets, and Fasotti (2009) used the Mental Slowness Questionnaire, the Mental Slowness Observation Test (Winkens, Van Heugten, Fasotti, \& Wade 2009), and the waterbed video task designed by Fasotti et al. (2000) to evaluate the effects of the Time Pressure Management strategies taught to stroke patients with mental slowness. The Mental Slowness Observation Test aims at performance on tasks, 
the Mental Slowness Questionnaire evaluates perceived consequences of mental slowness.

The Mental Slowness Observation Test consists of four tasks that are commonplace for most people, are brief, and amenable to accurate timing. The tasks are specifically designed to measure performance in time pressure situations: patients are required to handle incoming information and to work within certain time limits. The tasks are: (1) following a route description, (2) sorting money, (3) making a telephone call, and (4) looking up telephone numbers. The tester records the time needed to perform each task, and the number of elements achieved correctly. In addition, the number of strategies used are counted (for example, reiterating the information, asking the other speaker to slow down, etc.).

The Mental Slowness Questionnaire consists of 21 items examining different kinds of daily activities that are likely to be related to mental slowness. Examples of the items are: "I have trouble following a conversation" or "I have trouble doing two things at the same time". Each item is scored on a 5 -point frequency scale ranging from 0 (this never happens) to 4 (this happens often). Each problem is also scored on a 3-point severity scale ranging from 0 (not troublesome) to 2 (very troublesome). A weighted total, incorporating frequency and severity, is calculable.

The two instruments offer reliable and valid methods for measuring limitations in daily activities related to mental slowness and some of the consequences of mental slowness in terms of sense of time pressure, fatigue, depressive complaints and independent activities of daily living (ADL) functioning: internal consistency is acceptable for the Mental Slowness Observation Test (Cronbach's alpha $=.61$ and .73) and good for the Mental Slowness Questionnaire (alpha $=.91)$. For the Mental Slowness Observation Test correlations between the results of the two raters ranged between .77 and .99 and ICCs were between .86 and .99. For the Mental Slowness Questionnaire, correlations between two test occasions ranged between .85 and .90 and ICCs were between .91 and .95 .

\section{DISCUSSION}

The majority of studies $(n=274 ; 85 \%)$ that we found used measures of the speed of performance in particular cognitive tasks. Most of these measures, however, measure the speed of cognitive processes, and not the patient's actual performance in daily activities. In addition, neuropsychological tests tend to be administered at a single point in time but there are many withinperson factors (e.g., fatigue and anxiety) that are not constant across time. A person may perform the same test differently on a different day. Also, neuropsychological tests are designed to elicit a person's best performance under 
idealised circumstances, whereas real-life situations are rarely optimal: a person may perform well on a standardised test of mental processing but still perceive significant difficulties with mental slowness in daily life. And finally, most tests do not measure the effects of successful adaptive strategies.

Only seven studies used instruments that aimed at detecting the everyday consequences of mental slowness, assessing limitations in daily activities as well as the patient's experience of slowness.

These findings are in line with the conclusions that Cicerone et al. (2000, 2005) and Geusgens, Winkens, Van Heugten, Jolles, and Van den Heuvel (2007) drew in their review papers on evidence-based cognitive rehabilitation: most studies still assess treatment effectiveness by means of neuropsychological measures of impaired cognitive processing speed rather than by measures of the consequences in day-to-day life. In addition we found measures of general cognitive functioning and measures of general everyday functioning, where slowness was just one of several items that would affect the outcome and so was only partially measured.

The seven studies that measured the consequences of mental slowness used nine different measures. These measures all tried to detect the presence of mental slowness in terms of the (perceived) speed or accuracy with which patients performed all kinds of everyday tasks. Ponsford and Kinsella (1988) rated the speed with which participants performed day-to-day activities. Fasotti et al. (2000) used video tasks to study the accuracy with which persons with mental slowness processed and remembered information. Zhang et al. (2001) used a computer-simulated virtual reality environment to assess the ability of patients to process and sequence information involved in basic activities of daily living. Cicerone (2002) used a self-report measure rating how often patients had experienced difficulties in their day-to-day functioning. Whyte et al. (2004) used as measures of mental slowness the time needed and the accuracy with which people located items on a map or phone numbers in a directory, and the Ponsford and Kinsella Rating Scale of Attentional Behaviours. Winkens, Van Heugten, Wade, Habets, and Fasotti (2009) used an observation test aimed at performance on tasks, a questionnaire evaluating perceived consequences of mental slowness, and one of the video tasks designed by Fasotti et al. (2000).

The nine measures that have been used are not well studied. For some little or nothing is known about their psychometric properties. Others have only been used in one study, and some are cumbersome to administer (i.e., much equipment is needed) which may make them less useful in clinical settings. Only one measure focused on the perceived secondary consequences of mental slowness.

This review may have only identified seven studies for one or more reasons. We were interested in measures useful in stroke and TBI patients, and hence limited our search to these population groups. However, we do 
know of a few related studies with groups of healthy older adults using Timed Instrumental Activities of Daily Living (TIADL) tasks (Owsley, Sloane, McGwin, \& Ball, 2002). This measure consists of tasks sampling five common activities of daily living. The tasks address the following five IADL domains: (1) communication: finding a telephone number; (2) finance: giving change; (3) cooking: reading ingredients on a can of food; (4) shopping: finding items on a shelf; and (5) medicine: reading directions on a medicine bottle. For all tasks the examiner records the time taken to perform the task and whether the subject commits any errors in performing the task. The test has good test-retest reliability (Pearson correlation coefficient .85). The Road Sign Test has also been used to evaluate effects of interventions on everyday speed in healthy older adults (Roenker, Cissell, Ball, Wadley, \& Edwards, 2003; Jobe et al., 2001). In the Road Sign Test, participants view road signs (pedestrians, bicycle, right and left turn arrows) with and without a red slash. They are instructed to disregard signs with a red slash and to respond as quickly as possible, using a computer mouse, to signs without a slash. Accuracy of response is also recorded.

Second, the search was also limited by the great difficulty in identifying studies that were investigating "mental slowness". Mental slowness and information processing slowness are only two of a variety of terms that have been used to define how fast information is processed cognitively. Both terms are frequently used in the field of neuropsychology, but when used in the literature, there is little debate about (or explanation of) their meaning. They usually refer to either the time required to execute a cognitive task, or the amount of work that can be completed within a finite period of time (DeLuca \& Kalmar, 2007). Little or nothing is said, however, about possible resulting symptoms and complaints. Moving from the general term "mental slowness" to a consistent coherent construct is difficult; it cannot be understood in isolation from other cognitive abilities and other factors. Moving on to searchable terms is even more difficult and thus we will certainly have missed some studies of relevance and we possibly may have done so in a biased way.

The problem of agreeing and defining constructs used to describe and explain observations affects many concepts within neurology and neuropsychology, such as spasticity, neglect and apraxia. However, for some of these concepts, clear definitions have been made. Perhaps the term "mental slowness" is too general or over-inclusive. Our reconsideration of the concept of "mental slowness" is shown in Figure 2.

Kingstone, Smilek, Birmingham, Cameron, and Bischof (2005) plead that if one is to understand human functioning in everyday life then research needs to be grounded in the natural world and not solely in experimental paradigms. Such an approach involves studying what people actually do in everyday life, how they appear to be doing it, what they think they are doing, how they feel 


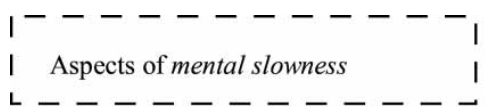

$1-----------1$

| Possible treatment for mental slowness |

ᄂ $---------\cdots$

Performance on structured specific cognitive tasks

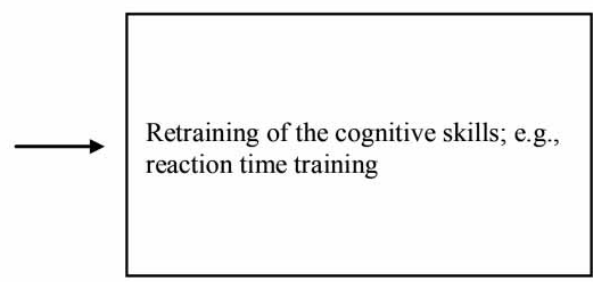

Observation by partner, employer and/or therapist of performance in non-automatic, novel or time-pressure daily activities

Perception by the patient of being slow

Perception of secondary consequences such as fatigue and tiredness, irritability, agitation and anxiety, and low mood
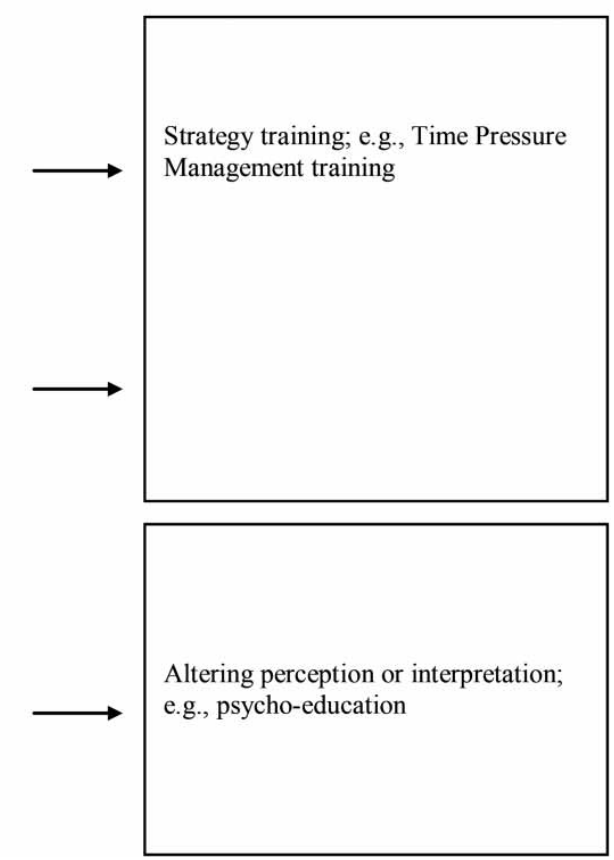

Figure 2. Conceptual model of mental slowness and its treatments.

about what they are doing, and so forth. We therefore think that any discussion on slowness or inaccuracy of a person's information processing system should consider at least all of the following aspects:

- First, patients may show slowed performance on a variety of specific cognitive tasks in laboratory settings.

- Second, patients may be observed (either by their partner, employer or therapist) to have difficulty or reduced effectiveness in performing 
everyday tasks that require fast and accurate information processing, such as having a conversation or driving a car.

- Third, patients may experience themselves as being slow.

- Finally, patients may experience secondary effects such as fatigue and tiredness arising from the extra effort required to achieve the desired output, and/or increased agitation or low mood when they experience they may be failing or performing less well.

We are aware that some problems described above may be caused by factors other than slowness alone, such as memory or attention problems, fatigue or depression. Nevertheless, we think that our consideration helps by acknowledging that there is more to mental slowness and to measuring the effects of treatment of mental slowness than considering performance on cognitive tests alone.

Figure 2 also shows that therapists should consider one or more of several rehabilitation treatments targeting the different aspects of mental slowness. For example, a strategy training teaching patients to cope successfully with the consequences of slowness may be very effective and may contribute to improvement in a variety of domains: it may improve performance on daily activities in terms of being more accurate and making fewer errors; it may reduce patients' feelings of being under pressure; it may decrease fatigue and tiredness; and it may even improve patients' mood.

It is important to have standardised, valid and reliable measures to assess these different aspects of mental slowness. The selection of outcome measures will depend upon the rationale for specific interventions or clinical goals. Primary outcome measures should be identified in relation to specific hypotheses and directly related to intended effects of treatment. There are several neuropsychological tests measuring speed of information processing. These can be very informative and can help identify the impairment underlying the observed problems. This is important since one first has to know what primary deficit causes the problems, and what deficit the intervention should aim at. But when patients are taught compensatory strategies to minimise the disabilities and participation problems in daily life arising, the effects should be measured in terms of activity performance and social participation using tools that focus on the experienced consequences. For some other cognitive functions this occurs already. For example, Zoccolotti, Antonucci, and Judica (1992) developed a semi-structured scale for the functional evaluation of hemi-inattention and used it to evaluate the effects of neglect training on everyday activities and functional independence. Similar comprehensive assessment of mental slowness should be done.

There are now a few published measures that focus on patients' perceptions of slowness and their performance in everyday life. When possible the performance of patients in real-life settings should be measured 
either by observation or, more practically, through self-report or reports of partners or family. Next, the extent of secondary fatigue and emotional disturbance should be measured. Finally, qualitative studies might ask patients about their experience of mental slowness, time pressure and related aspects and their success at adjusting their behaviour to minimise adverse experiences.

\section{REFERENCES}

Anderson, J. R. (1993). Rules of the mind. Hillsdale, NJ: Lawrence Erlbaum.

Ballard, C., Stephen, S., Kenny, R., Kalaria, R., Tovee, M., \& O’Brien, J. (2003). Profile of neuropsychological deficits in older stroke survivors without dementia. Dementia and Geriatric Cognitive Disorders, 16(1), 52-56.

Barrow, I. M. (2001). Within category naming in mild traumatic brain injured and normal adults. Dissertation Abstracts International: Section B: The Sciences and Engineering, 62(1-B), 205.

Bate, A. J., Mathias, J. L., \& Crawford, J. R. (2001). The covert orienting of visual attention following severe traumatic brain injury. Journal of Clinical and Experimental Neuropsychology, 23(3), 386-398.

Bay, E., \& Donders, J. (2008). Risk factors for depressive symptoms after mild-to-moderate traumatic brain injury. Brain Injury, 22(3), 233-241.

Bleiberg, J., Kane, R. L., Reeves, D. L., Garmoe, W. S., \& Halpern, E. (2000). Factor analysis of computerized and traditional tests used in mild brain injury research. Clinical Neuropsychologist, 14(3), 287-294.

Brodaty, H., Sachdev, P. S., Withall, A., Altendorf, A., Valenzuela, M. J., \& Lorentz, L. (2005). Frequency and clinical, neuropsychological and neuroimaging correlates of apathy following stroke. The Sydney Stroke Study. Psychology Medicine, 35(12), 1707-1716.

Brouwer, W. H., Withaar, F. K., Tant, M. C., \& Van Zomeren, A. H. (2002). Attention and driving in traumatic brain injury: A question of coping with time pressure. Journal of Head Trauma Rehabilitation, 17(1), 1-15.

Brown, D. G. J., Burnett-Stolnack, M., Hashimoto, N., Hier-Wellmer, S., Perlman, O. Z., \& Seigerman, C. (1996). The relationship of neuropsychological status and productive outcomes following traumatic brain injury. Brain Injury, 10(9), 663-676.

Carlson, M. C. (1996). The impact of past mild head injury on attention. Dissertation Abstracts International: Section B: The Sciences and Engineering, 57(1-B), 732.

Cicerone, K. D. (2002). Remediation of "working attention" in mild traumatic brain injury. Brain Injury, 16(3), 185-195.

Cicerone, K. D., Dahlberg, C., Kalmar, K., Langenbahn, D. M., Malec, J. F., Bergquist, T. F., et al. (2000). Evidence-based cognitive rehabilitation: Recommendations for clinical practice. Archives of Physical Medicine and Rehabilitation, 81(12), 1596-1615.

Cicerone, K. D., Dahlberg, C., Malec, J. F., Langenbahn, D. M., Felicetti, T., Kneipp, S., et al. (2005). Evidence-based cognitive rehabilitation: Updated review of the literature from 1998 through 2002. Archives of Physical Medicine and Rehabilitation, 86, 1681-1692.

Collins, L. F., \& Long, C. J. (1996). Visual reaction time and its relationship to neuropsychological test performance. Archives of Clinical Neuropsychology, 11(7), 613-623.

Crawford, M. D., Knight, R. G., \& Alsop, B. L. (2007). Speed of word retrieval in postconcussion syndrome. Journal of the International Neuropsychological Society, 13(1), 178-182. 
DeGuise, E., Feyz, M., Leblanc, J., Richard, S. L., \& Lamoureux, J. (2005). Overview of traumatic brain injury patients at a tertiary trauma centre. Canadian Journal of Neurological Sciences, 32(2), 186-193.

DeLuca, J., \& Kalmar, J. H. (2007). Information processing speed in clinical populations. Hove, UK: Psychology Press.

Dik, M. G., Deeg, D. J., Bouter, L. M., Corder, E. H., Kok, A., \& Jonker, C. (2000). Stroke and apolipoprotein E epsilon4 are independent risk factors for cognitive decline: A populationbased study. Stroke, 31(10), 2431-2436.

Duits, A., Munnecom, T., Van Heugten, C., \& Van Oostenbrugge, R. J. (2008). Cognitive complaints in the early phase after stroke are not indicative of cognitive impairment. Journal of Neurology, Neurosurgery and Psychiatry, 79(2), 143-146.

Ebner, A., Haas, J. C., Lucking, C. H., Schily, M., Wallesch, C. W., \& Zimmermann, P. (1986). Event-related brain potentials (P300) and neuropsychological deficit in patients with focal brain lesions. Neuroscience Letters, 64(3), 330-334.

Erlanger, D. M., Kausnik, T., Broshek, D., Freeman, J., Feldman, D., \& Festa, J. (2002). Development and validation of a web-based screening tool for monitoring cognitive status. Journal of Head Trauma Rehabilitation, 17(5), 458-476.

Erlanger, D., Feldman, D., Kutner, K., Kaushik, T., Kroger, H., Festa, J., Barth, J., Freeman, J., \& Broshek, D. (2003). Development and validation of a web-based neuropsychological test protocol for sports-related return-to-play decision-making. Archives of Clinical Neuropsychology, 18(3), 293-316.

Fasotti, L., Kovacs, F., Eling, P. A. T. M., \& Brouwer, W. H. (2000). Time Pressure Management as a compensatory strategy training after closed head injury. Neuropsychological Rehabilitation, 10(1), 47-65.

Fazio, V. C., Lovell, M. R., Pardini, J. E., \& Collins, M. W. (2007). The relation between postconcussion symptoms and neurocognitive performance in concussed athletes. NeuroRehabilitation, 22(3), 207-216.

Felmingham, K. L., Baguley, I. J., \& Green, A. M. (2004). Effects of diffuse axonal injury on speed of information processing following severe traumatic brain injury. Neuropsychology, $18(3), 564-571$.

Fisk, G. D., \& Mennemeier, M. (2006). Common neuropsychological deficits associated with stroke survivors' impaired performance on a useful field of view test. Perceptual Motor Skills, 102(2), 387-394.

Formisano, R., Bivona, U., Brunelli, S., Giustini, M., \& Taggi, F. (2001). Driving competence after severe brain injury: A retrospective study. Europa Medicophysica, 37(4), 257-266.

Fos, L. A., Greve, K. W., South, M. B., Mathias, C., \& Benefield, H. (2000). Paced Visual Serial Addition Test: An alternative measure of information processing speed. Applied Neuropsychology, 7(3), 140-146.

Galski, T., Ehle, H. T., \& Williams, J. B. (1997). Off-road driving evaluations for persons with cerebral injury: A factor analytic study of predriver and simulator testing. American Journal of Occupational Therapy, 51(5), 352-359.

Gerritsen, M. J., Berg, I. J., Deelman, B. G., Visser-Keizer, A. C., \& Meyboom-de Jong, B. (2003). Speed of information processing after unilateral stroke. Journal of Clinical and Experimental Neuropsychology, 25(1), 1-13.

Geurts, A. C., Knoop, J. A., \& Van Limbeek, J. (1999). Is postural control associated with mental functioning in the persistent postconcussion syndrome? Archives of Physical Medicine and Rehabilitation, 80(2), 144-149.

Geusgens, C. A. V., Winkens, I., Van Heugten, C. M., Jolles, J., \& Van den Heuvel, W. J. A. (2007). The occurrence and measurement of transfer in cognitive rehabilitation: A critical review. Journal of Rehabilitation Medicine, 39(6), 425-439. 
Grigsby, J., Rosenberg, N. L., \& Busenbark, D. (1995). Chronic pain is associated with deficits in information processing. Perceptual and Motor Skills, 81(2), 403-410.

Gron, G. (1996). Cognitive slowing in patients with acquired brain damage: An experimental approach. Journal of Clinical and Experimental Neuropsychology, 18(3), 406-415.

Heitger, M. H., Jones, R. D., Dalrymple-Alford, J. C., Frampton, C. M., Ardagh, M. W., \& Anderson, T. J. (2006). Motor deficits and recovery during the first year following mild closed head injury. Brain Injury, 20(8), 807-824.

Hinton-Bayre, A. D., Geffen, G., \& McFarland, K. (1997). Mild head injury and speed of information processing: A prospective study of professional rugby league players. Journal of Clinical and Experimental Neuropsychology, 19(2), 275-289.

Hochstenbach, J., Mulder, T., Van Limbeek, J., Donders, R., \& Schoonderwaldt, H. (1998). Cognitive decline following stroke: A comprehensive study of cognitive decline following stroke. Journal of Clinical and Experimental Neuropsychology, 20, 503-517.

Iverson, G. L., Brooks, B. L., Collins, M. W., \& Lovell, M. R. (2006). Tracking neuropsychological recovery following concussion in sport. Brain injury, 20(3), 245-252.

Jobe, J. B., Smith, D. M., Ball, K., Tennstedt, S. L., Marsiske, M., Willis, S. L., et al. (2001). ACTIVE: A cognitive intervention trial to promote independence in older adults. Controlled Clinical Trials, 22(4), 453-479.

Johnstone, B., Schopp, L. H., Harper, J., \& Koscuilek, J. (1999). Neuropsychological impairments, vocational outcomes, and financial costs for individuals with traumatic brain injury receiving state vocational rehabilitation services. Journal of Head Trauma Rehabilitation, 14(3), 220-232.

Kingstone, A., Smilek, D., Birminghan, E., Cameron, D., \& Bischof, W. F. (2005). Cognitive ethology: Giving real life to attention research. In J. Duncan, P. McLeod, \& L. H. Phillips (Eds.), Measuring the mind: speed, control and age. New York, NY: Oxford University Press.

Klonoff, P. S., Talley, M. C., Dawson, L. K., Myles, S. M., Watt, L. M., Gehrels, J. A., \& Henderson, S. W. (2007). The relationship of cognitive retraining to neurological patients' work and school status. Brain Injury, 21(11), 1097-1107.

Korda, R. J., \& Douglas, J. M. (1997). Attention deficits in stroke patients with aphasia. Journal of Clinical and Experimental Neuropsychology, 19(4), 525-542.

Korteling, J. E. (1990). Perception-response speed and driving capabilities of brain damaged and older drivers. Human Factors, 32(1), 95-108.

Laidlaw, T. M. (1993). Hypnosis and attention deficits after closed head injury. International Journal of Clinical and Experimental Hypnosis, 41(2), 97-111.

Lang, D. L. (2000). Subtyping closed head injury patients using the Dean-Woodcock Neuropsychological Assessment System, Dissertation Abstracts International: Section B: The Sciences and Engineering, 60(11-B), 5804.

Lee, D., LoGalbo, A. P., Banos, J. H., \& Novack, T. A. (2004). Prediction of cognitive abilities 1 year following traumatic brain injury from inpatient rehabilitation cognitive screening. Rehabilitation Psychology, 49(2), 167-171.

Leskela, M., Hietanen, M., Kalska, H., Ylikoski, R., Pohjasvaara, T., Mantyla, R., \& Erkinjuntii, T. (1999). Executive functions and speed of mental processing in elderly patients with frontal or nonfrontal ischemic stroke. European Journal of Neurology, 6(6), 653-661.

Lippert-Gruner, M., Kuchta, J., Hellmich, M., \& Klug, N. (2006). Neurobehavioural deficits after severe traumatic brain injury (TBI). Brain Injury, 20(6), 569-574.

Loranger, M., Lussier, J., Pepin, M., Hopps, S. L., \& Senecal, B. (2000). Information-processing speed and assessment of early response latency among stroke patients. Psychology Report, 87(3 Pt 1), 893-900. 
Mazer, B. L., Sofer, S., Korner-Bitensky, N., \& Gelinas, I. (2001). Use of the UFOV to evaluate and retrain visual attention skills in clients with stroke: A pilot study. American Journal of Occupational Therapy, 55(5), 552-557.

Millis, S. R., Rosenthal, M., \& Lourie, I. F. (1994). Predicting community integration after traumatic brain injury with neuropsychological measures. International Journal of Neurosciences, 79(3-4), 165-167.

O'Jile, J. R., Ryan, L. M., Betz, B., Parks-Levy, J., Hilsabeck, R. C., Rhudy, J. L., \& Gouvier, W. D. (2006). Information processing following mild head injury. Archives of Clinical Neuropsychology, 21(4), 293-296.

Owsley, C., Sloane, M., McGwin, G. Jr., \& Ball, K. (2002). Timed instrumental activities of daily living tasks: Relationship to cognitive function and everyday performance assessments in older adults. Gerontology, 48(4), 254-265.

Petry, M. C., Crosson, B., Gonzalez-Rothi, L. J., Bauer, R. M., \& Schauer, C. A. (1994). Selective attention and aphasia in adults: Preliminary findings. Neuropsychologia, 32(11), 1397-1408.

Ponsford, J., Draper, K., \& Schonberger, M. (2008). Functional outcome 10 years after traumatic brain injury: Its relationship with demographic, injury severity, and cognitive and emotional status. Journal of the International Neuropsychological Society, 14(2), 233-242.

Ponsford, J. L., \& Kinsella, G. (1988). Evaluation of a remedial program for attention deficits following closed head injury. Journal of Clinical and Experimental Neuropsychology, 10(6), 69-708.

Ponsford, J., \& Kinsella, G. (1991). The use of a rating scale of attentional behavior. Neuropsychological Rehabilitation, 1(4), 241-257.

Ponsford, J., \& Kinsella, G. (1992). Attentional deficits following closed-head injury. Journal of Clinical and Experimental Neuropsychology, 14(5), 822-838.

Ponsford, J., Willmont, C., Rothwell, A., Cameron, P., Kelly, A. M., Nelms, R., Curran, C., \& $\mathrm{Ng}$, K. (2000). Factors influencing outcome following mild traumatic brain injury in adults. Journal of the International Neuropsychological Society, 6(5), 568-579.

Ponsford, J., \& Ziino, C. (2003). Fatigue and attention following traumatic brain injury. Zeitschrift fur Neuropsychologie, 14(3), 155-163.

Posner, M. I., \& Snyder, C. R. (1975). Attention and cognitive control. In R. L. Solso (Ed.), Information processing and cognition: The Loyola Symposium. Hillsdale, NJ: Erlbaum.

Pouthas, V., \& Perbal, S. (2004). Time perception depends on accurate clock mechanisms as well as unimpaired attention and memory processes. Acta Neurobiologiae Experimentalis, 64(3), 367-385.

Rasquin, S. M., Lodder, J., Ponds, R. W., Winkens, I., Jolles, J., \& Verhey, F. R. (2004). Cognitive functioning after stroke: A one-year follow-up study. Dementia and Geriatric Cognitive Disorders, 18, 138-144.

Robertson, I. H., Ward, T., Ridgeway, V., \& Nimmo-Smith, I. (1996). The structure of normal human attention: The test of everyday attention. Journal of the International Neuropsychological Society, 2, 525-534.

Roenker, D. L., Cissell, G. M., Ball, K. K., Wadley, V. G., \& Edwards, J. D. (2003). Speed of processing and driving simulator training result in improved driving performance. Human Factors, 45, 218-233.

Ruff, R. M., Niemann, H., Allen, C. C., Farrow, C. E., \& Wylie, T. (1992). The Ruff 2 and 7 Selective Attention Test: A neuropsychological application. Perceptual Motor Skills, 75(3 Pt 2), 1311-1319.

Salthouse, T. A. (1996). The processing-speed theory of adult age differences in cognition. Psychology Review, 103(3), 403-428.

Shiffrin, R. M., \& Schneider, W. (1977). Controlled and automatic human information processing; II: Perceptual learning, automatic attending and a general theory. Psychology Review, 84, 127-190. 
Sosnoff, J. J., Broglio, S. P., Hillman, C. H., \& Ferrara, M. S. (2007). Concussion does not impact intraindividual response time variability. Neuropsychology, 21(6), 796-802.

Spikman, J. M., Timmerman, M. E., Van Zomeren, A. H., \& Deelman, B. G. (1999). Recovery versus retest effects in attention after closed head injury. Journal of Clinical and Experimental Neuropsychology, 21(5), 585-605.

Stuss, D. T., Stethem, L. L., Hugenholtz, H., Picton, T., Pivik, J., \& Richard, M. T. (1989). Reaction time after head injury: Fatigue, divided and focused attention, and consistency of performance. Journal of Neurology, Neurosurgery and Psychiatry, 52(6), 742-748.

Tate, R. L., \& Broe, G. A. (1999). Psychosocial adjustment after traumatic brain injury: What are the important variables? Psychological Medicine, 29(3), 713-725.

Timmerman, M. E., \& Brouwer, W. H. (1999). Slow information processing after very severe closed head injury: Impaired access to declarative knowledge and intact application and acquisition of procedural knowledge. Neuropsychologia, 37, 467-478.

Tombaugh, T. N., Rees, L., Stormer, P., Harrison, A. G., \& Smith, A. (2007). The effects of mild and severe traumatic brain injury on speed of information processing as measured by the computerized tests of information processing (CTIP). Archives of Clinical Neuropsychology, 22(1), 25-36.

Van Zomeren, A. H., \& Spikman, J. M. (2003). Tempo en aandacht. In J. A. M. Vandermeulen, M. M. A. Derix, C. J. J. Avezaat, Th. Mulder, \& J. W. Van Strien (Eds.), Niet aangeboren hersenletsel bij volwassenen. The Netherlands: Elsevier Gezondheidszorg.

Watt, N., \& Penn, C. (2000). Predictors and indicators of return to work following traumatic brain injury in South Africa: Findings from a preliminary experimental database. South African Journal of Psychology, 30(3), 27-37.

Whyte, J., Hart, T., Vaccaro, M., Grieb-Neff, P., Risser, A., Polansky, M., et al. (2004). Effects of methylphenidate on attention deficits after traumatic brain injury: A multidimensional, randomized, controlled trial. American Journal of Physical Medicine and Rehabilitation, $8(6), 401-420$.

Winkens, I., Van Heugten, C. M., Fasotti, L., Duits, A. A., \& Wade, D. T. (2006). Manifestations of mental slowness in the daily life of stroke patients. Clinical Rehabilitation, 20, 827-834.

Winkens, I., Van Heugten, C. M., Fasotti, L., \& Wade, D. T. (2009). Reliability and validity of two new instruments for measuring aspects of mental slowness in the daily lives of stroke patients. Neuropsychological Rehabilitation, 19(1), 64-85.

Winkens, I., Van Heugten, C. M., Wade, D. T., Habets, E., \& Fasotti, L. (2009). Archives of Physical Medicine and Rehabilitation, 90(10), 1672-1679.

Zhang, L., Abreu, B. C., Masel, B., Scheibel, R. S., Christiansen, C. H., Huddleston, N., et al. (2001). Virtual reality in the assessment of selected cognitive function after brain injury. American Journal of Physical Medicine and Rehabilitation, 80(8), 597-604.

Zhang, L., Abreu, B. C., Seale, G. S., Masel, B., Christiansen, C. H., \& Ottenbacher, K. J. (2003). A virtual reality environment for evaluation of a daily living skill in brain injury rehabilitation: Reliability and validity. Archives of Physical Medicine and Rehabilitation, 84(8), 1118-1124.

Zoccolotti, P., Antonucci, G., \& Judica, A. (1992). Psychometric characteristics of two semistructured scales for the functional evaluation of hemi-inattention in extrapersonal and personal space. Neuropsychological Rehabilitation. 2(3), 179-191.

Manuscript received November 2010 Revised manuscript received September 2011 


\section{APPENDIX}

Details of literature search in MEDLINE

Similar terms (Thesaurus terms and free text words) were used in the other databases.

\begin{tabular}{lcc}
\hline & Text words/MESH TERMS & \\
\hline Cognitive functioning & \multicolumn{1}{c}{ Type of brain injury } & \multicolumn{1}{c}{ Limits } \\
\hline (slow* AND (mental* OR $^{*}$ & CEREBROVASCULAR ACCIDENT OR & Human studies, \\
perceive* OR cognit* OR & CEREBROVASCULAR DISORDERS OR & $>18$ yrs, \\
(information) process* OR & BRAIN INJURIES OR stroke OR ischem* & English/Dutch \\
tempo)) OR & OR hemorrhag* OR brain injury* OR brain & \\
(speed* AND (mental* OR & lesion* OR head injury* OR brain \\
perceive* OR cognit* OR & $\begin{array}{l}\text { concussion* OR brain damage* OR brain } \\
\text { (information) process*)) OR } \\
\text { inforct* OR brain embolism OR brain }\end{array}$ \\
\hline
\end{tabular}

* = wild card, such that it would include all possible transformations of the term. For example "brain damage*" includes "brain damages", "brain damaging", "damaged brain", etc. 